\title{
Radical Chlorination of Polyethylene and Molecular Structure Characterization of Reaction Products
}

\author{
Ali Moradi, Ahmad RamaZani S.A., ${ }^{\dagger}$ and Mohammad SHAHRoKHI \\ Chem. Eng. and Petrol. Dept., Sharif University of Technology, P. O. Box 11365-9456, Teharn, Iran
}

(Received December 13, 2004; Accepted June 23, 2005; Published September 15, 2005)

\begin{abstract}
In this research the radical chlorination reaction of polyethylene has been carried out in perchloroethylene solvent under atmospheric pressure, using chlorine gas and UV light. In order to characterize the structural configuration of chlorinated polymer and study the reaction rate, different samples have been taken in equal periods of time during the reaction time. The FT-IR and H NMR spectra of these samples have been recorded and interpreted. The sequences of methylene groups between two subsequent chloromethylene groups in the polymeric chains have been determined through H NMR spectra and the obtained results have been confirmed with the data of some model compounds. The relative percentage of these methylene groups, which have been calculated from their integrated values in their H NMR spectra have been plotted vs. percentage of chlorination and discussed. Also H NMR spectra have been used for calculating the chlorine percentage of each sample and the results have been compared with data obtained from an elemental analyzing technique namely flask combustion method. Using the results of these two techniques, the reaction rate has been plotted versus reaction time and compared. [DOI 10.1295/polymj.37.661]
\end{abstract}

KEY WORDS Chlorinated Polyethylene (CPE) / Radical Chlorination / H NMR Analyzing /

Chlorinated polyethylene (CPE), depending on its degree of chlorination, has several applications such as property modifier in blends with many other polymers (especially polyvinylchloride (PVC)), wire and cable covering, adhesive, floor tile, membrane and also as a thermoplastic elastomer. ${ }^{1-3}$ The physical and mechanical properties of CPE highly depend on degree of chlorination, microstructure of polymer chains, method of production, polyethylene (PE) and solvent types. The rate of the chlorination strongly depends on the distribution and content of substituted chlorine atoms along the CPE's chains. As more and more chlorine atoms are substituted on the polyethylene chain, the crystalline fraction of it gradually reduce and so converts to a softer and more flexible product. At low chlorine content the CPE product is still hard. Above $10 \%$ of chlorination the elasticity and flexibility of product begin to increase progressively and at $35-40 \%$ chlorination the reaction product becomes the thermoplastic elastomer. Above $55 \%$ of chlorination, the hardness and toughness of chlorinated polyethylene again starts to increase..$^{4-12}$

There are two main types of chlorination process namely; the solution phase and the suspension phase. In the method of solution phase the chlorine atoms are substituted along the backbone of polymer randomly and homogenously and the obtained CPE has amorphous structure. Most of industrial units produce various kinds of CPE's in the solution phase using a single solvent such as $\mathrm{CCl}_{4}$ or a mixture of solvents. ${ }^{4-12}$ Chlorination reaction in the suspension phase mostly happens on the surface of the polymer particles and so the structure of procured product is blocky and non-uniform. ${ }^{1-3,9}$ In addition chlorine content of this process product is low and cannot be used for some applications that needs high chlorine content CPE. Both of these methods are usually carried out under a moderate pressure. Radical chlorination of polyethylene films in the heterogeneous solid-gas phase is another method of reaction that has been studied more recently. ${ }^{13,14}$ The polymer films that are chemically modified in this way have already found some interesting applications such as membrane technology. ${ }^{15}$

Radical chlorination of polyethylene is generally an issue, which has not been completely investigated and still can be studied from different features such as effects of physical and chemical conditions (pressure, temperature and type of solvent), kinetic and rate of reaction, modeling and simulation of process and structural configuration of products. All of these fields normally require a lot of experimental data and analyzing information that can be obtained during progress of chlorination reactions.

Some authors have used the infrared spectroscopy technique to analyze the molecular structure of chlorine containing polymers. These articles have been presented either to interpret the appeared peaks in the IR spectra, or to elucidate the distributions of chlorine atoms on the polymeric chains, for instance distinguishing of random or blocky regions. ${ }^{16-22}$ Another aspect of these studies is the qualitative characterization of chlorine atoms and providing a supporting evidence

${ }^{\dagger}$ To whom correspondence should be addressed (Tel: +98-21-6005819, Fax: +98-21-6022853, E-mail: ramazani@sharif.edu). 
for NMR studies. Some researchers have used ${ }^{13} \mathrm{C}$ NMR to analyze the CPE's products. They have used the chemical shifts assigned to $-\mathrm{CH}_{2}-,-\mathrm{CHCl}-$, $-\mathrm{CCl}_{2}-$ to determine the chlorine distribution. ${ }^{20-24}$

Less research has been done for characterization of the CPE's products based on H NMR analyzing technique. Since the protons of the methylene $\left(\mathrm{CH}_{2}\right)$, methyl $\left(\mathrm{CH}_{3}\right)$ and chloromethylene $(\mathrm{CHCl})$ chemical groups appear in a completely separate chemical shifts at the CPE's H NMR spectra, this analyzing technique ( $\mathrm{H} \mathrm{NMR} 500 \mathrm{MHz}$ ) is used for characterizing the sequences of these chemical groups, and it also has been used to determine the degree of chlorination.

A few attempts have been also tried for producing CPE in atmospheric pressure. ${ }^{25-27}$ The benefits of chlorination of polyethylene under atmospheric pressure, besides of economical feature, are easier control of the reaction and ease of data gathering for kinetic studies. In this research many reactions have been carried out under atmospheric pressure in perchloroethylene solvent at different conditions such as reaction temperature, polyethylene types (Low and high density) and their concentrations and type of initiators (UV light and chemical initiators such as benzoyl peroxide).

The structural configuration of polymeric chain that obtained during reaction has been characterized using the FT-IR and H NMR spectra of samples. The samples have been taken periodically during the reaction time. The sequences of methylene and chloromethylene groups and the degree of chlorination or chlorine content have been calculated from the CPE's H NMR spectra and results are compared to the elemental analyzing techniques.

The paper has been organized as follows. Firstly, reaction mechanism, materials and equipments are described. Next experimental procedure is explained and finally the results obtained from FT-IR, H NMR and flask combustion analyzing method are discussed.

\section{REACTION MECHANISM}

The overall reaction of radical chlorination of polyethylene is as follows:

$$
-\mathrm{CH}_{2} \mathrm{CH}_{2} \mathrm{CH}_{2} \mathrm{CH}_{2} \mathrm{CH}_{2} \mathrm{CH}_{2}-+\mathrm{Cl}_{2} \stackrel{\text { UV }}{\longrightarrow}-\mathrm{CH}_{2} \mathrm{CH}_{2} \mathrm{CHClCH}_{2} \mathrm{CH}_{2}-+\mathrm{HCl}
$$

The following equations elucidate the steps of radical chlorination reaction of $\mathrm{PE}:^{1-3}$

Initiation:

$$
\mathrm{Cl}_{2} \stackrel{\text { uv }}{\longrightarrow} 2 \stackrel{*}{\mathrm{Cl}}
$$

Propagation:

$$
\begin{aligned}
& -\mathrm{CH}_{2} \mathrm{CH}_{2} \mathrm{CH}_{2} \mathrm{CH}_{2} \mathrm{CH}_{2}-+\stackrel{*}{\mathrm{Cl}} \longrightarrow-\mathrm{CH}_{2} \mathrm{CH}_{2} \stackrel{*}{\mathrm{C}} \mathrm{HCH}_{2} \mathrm{CH}_{2}-+\mathrm{HCl} \\
& -\mathrm{CH}_{2} \mathrm{CH}_{2} \stackrel{*}{\mathrm{C}} \mathrm{HCH}_{2} \mathrm{CH}_{2} \mathrm{CH}_{2}-+\mathrm{Cl}_{2} \longrightarrow-\mathrm{CH}_{2} \mathrm{CH}_{2} \mathrm{CHClCH}_{2} \mathrm{CH}_{2}-+\stackrel{*}{\mathrm{Cl}}
\end{aligned}
$$

Termination:

$$
\begin{aligned}
& \stackrel{*}{\mathrm{C}}+\stackrel{*}{\mathrm{C}} \mathrm{l} \longrightarrow \mathrm{Cl}_{2} \\
& \stackrel{*}{\mathrm{Cl}}+-\mathrm{CH}_{2} \mathrm{CH}_{2} \stackrel{*}{\mathrm{C}} \mathrm{HCH}_{2} \mathrm{CHCl}-\longrightarrow-\mathrm{CH}_{2} \mathrm{CH}_{2} \mathrm{CHClCH}_{2} \mathrm{CHCl}- \\
& -\mathrm{CH}_{2} \mathrm{CH}_{2} \stackrel{*}{\mathrm{CHCH}} \mathrm{H}_{2} \mathrm{CHCl}-+-\mathrm{CH}_{2} \mathrm{CH}_{2} \stackrel{*}{\mathrm{CHCH}_{2} \mathrm{CHCl}-\longrightarrow} \\
& -\mathrm{CH}_{2} \mathrm{CH}_{2} \mathrm{CHCH}_{2} \mathrm{CHCl}- \\
& -\mathrm{CH}_{2} \mathrm{CH}_{2} \mathrm{CHCH}_{2} \mathrm{CHCl}- \\
& \text { or } \begin{array}{r}
-\mathrm{CH}_{2} \mathrm{CH}=\mathrm{CHCH}_{2} \mathrm{CHCl}- \\
+-\mathrm{CH}_{2} \mathrm{CH}_{2} \mathrm{CH}_{2} \mathrm{CH}_{2} \mathrm{CHCl}-
\end{array}
\end{aligned}
$$

One can see that the radical chlorination reaction of $\mathrm{PE}$ can be considered as a chain reaction having initiation, propagation and termination steps. Of course, it has some differences in its propagation and termination steps compared to classical free radical mechanism such as polymerization reactions. A similar reaction scheme, with some minor differences, can be considered for radical chlorination in the presence of chemical initiators.

\section{EXPERIMENTS}

\section{Materials and Equipments}

The HDPE (with density of $0.994 \mathrm{~g} / \mathrm{cm}^{3}$ ) was prepared from Iranian Petrochemical Company. Chlorine gas with a purity of $99.5 \%$ from Chloran Company of Iran was used. An industrial grade of perchloroethylene after twice distillation was used. The other chem- 


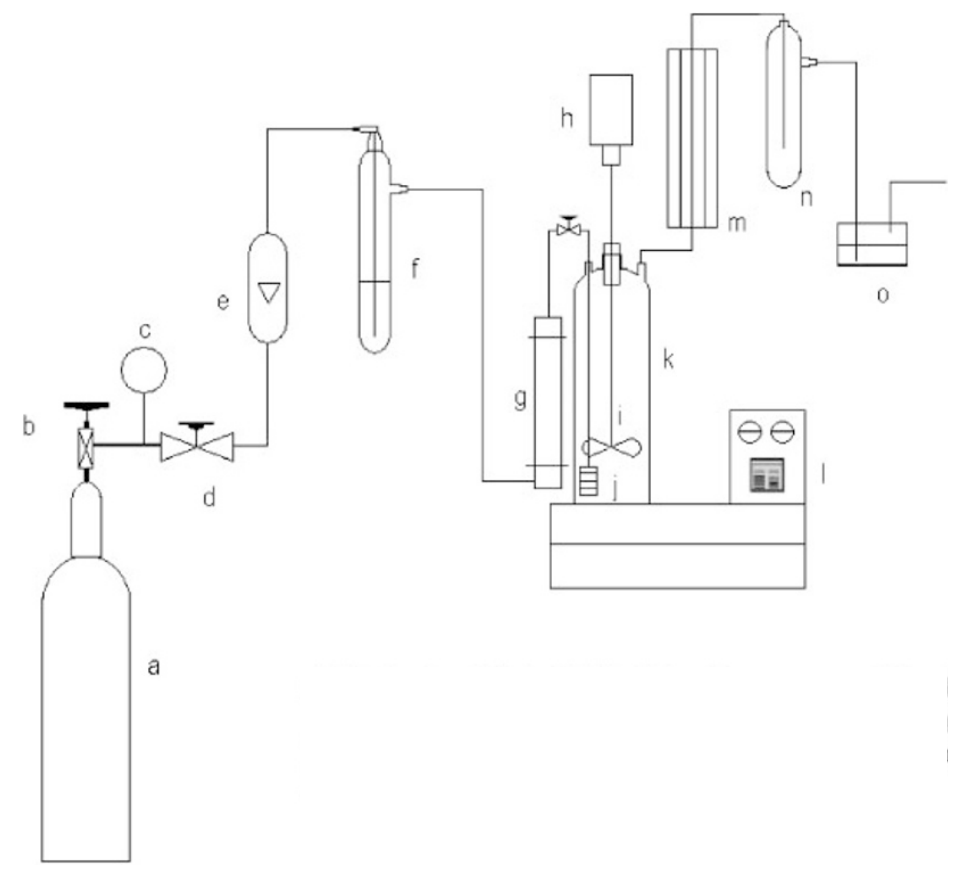

Figure 1. Schematic diagram of the setup: (a) chlorine gas cylinder, (b) main valve, (c) pressure gage, (d) needle valve, (e) rotameter, (f) Trap, (g) UV cell, (h) mechanical mixer, (i) impeller, (j) gas sparger, (k) 5 mouth reactor, (l) hot oil circulator, (m) condenser, (n) trap, (o) neutralization system.

icals such as methanol and analyzing chemicals were prepared from Merck Company.

The Fourier Transfer Infrared (FT-IR) spectrophotometer, Bomem model MB100, and a Nuclear Magnetic Resonance (NMR) spectrometer, Bruken Drx-500 Avance, have been used to take the FT-IR and H NMR spectra of CPE's samples. An elemental analyzing method, flask combustion method (IP-244) has been also applied for determining the chlorine content of products. ${ }^{28}$

An experimental setup was made for performing of PE photochlorination whose schematic diagram is shown in Figure 1. This setup comprises; a 2 L cylindrical reactor equipped with some other accessories such as a gas sparger, a UV cell with a 30 Watt UV lamp and a reflux system, a variable speed (0-800 rpm) mechanical mixer, a gas flow meter and a neutralization system for exhaust gas.

\section{EXPERIMENT PROCEDURE}

Many reactions under atmospheric pressure were carried out in order to determine the appropriate conditions for chlorination of polyethylene. It has been finally found that the temperature of 100 degree centigrade and 5\% (by weight) concentration of PE in solvent (perchloroethylene) are suitable.

In the first step of operation the reactor was charged with $800 \mathrm{~mL}$ of perchloroethylene and $60 \mathrm{~g}$ of HDPE. Polyethylene was dissolved in the boiling perchloroethylene via mechanical mixing during $30 \mathrm{~min}$.
The reaction was established by sparging chlorine gas at a rate of $0.3 \mathrm{~L} / \mathrm{min}$ and temperature about $100^{\circ} \mathrm{C}$. During the $7: 30 \mathrm{~h}$ of reaction the obtained final product contains about $65 \%$ of chlorine. Samples have been taken every $50 \mathrm{~min}$. At the end of the reaction time $(7: 30 \mathrm{~h})$, the sparging of chlorine gas was stopped and the solution was allowed to stir one hour more. The samples and final product were washed with methanol and then dried in a vacuum oven under -0.8 bar at $80^{\circ} \mathrm{C}$ temperature for $24 \mathrm{~h}$. For taking IR spectra the samples were prepared as films with a thickness of about $0.2 \mathrm{~mm}$. The dried samples were dissolved in perchloroethylene at the concentration of about $1 \%(\mathrm{w} / \mathrm{w})$ and then the $\mathrm{H}$ NMR spectra were taken from them in the presence of $\mathrm{C}_{6} \mathrm{D}_{6}$ at $85^{\circ} \mathrm{C}$. It should be mentioned that $\mathrm{C}_{6} \mathrm{D}_{6}$ is chosen because at this temperature the $\mathrm{CPE}$ is completely dissolved in this solvent.

\section{RESULTS AND DISCUSSIONS}

The CPE's FT-IR spectra compared to the initial PE spectra show considerable changes such as the appearance of new peaks and the displacement of original peaks. Before any prejudgment it is preferred to study the IR spectra of the polyethylene which has been used in these experiments. Figure 2 illustrates the FT-IR spectrum of HDPE. The absorption peaks appeared at 717 and $1465 \mathrm{~cm}^{-1}$ are assigned to the bending modes of $\mathrm{CH}_{2}$ atoms where the peak appeared at the region of $2850-2950 \mathrm{~cm}^{-1}$ is assigned 


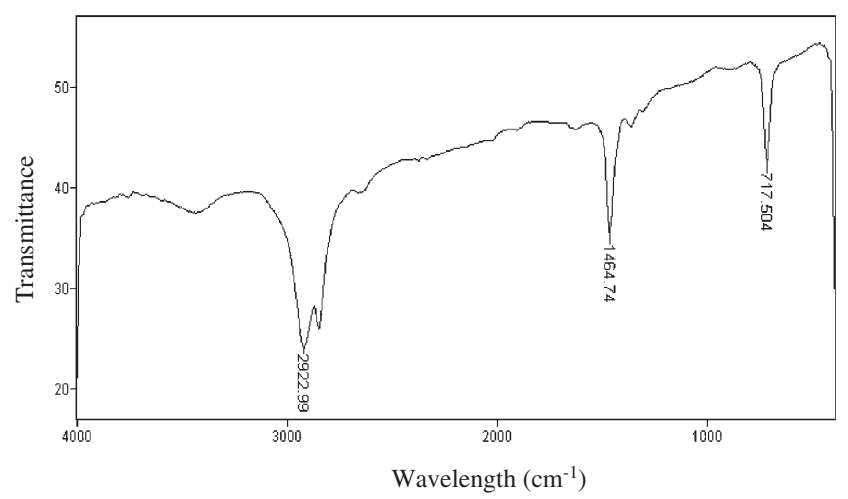

Figure 2. The FT-IR spectrum of HDPE powder.



Figure 3. The FT-IR spectrum of CPE sample containing $13.5 \%$ chlorine.

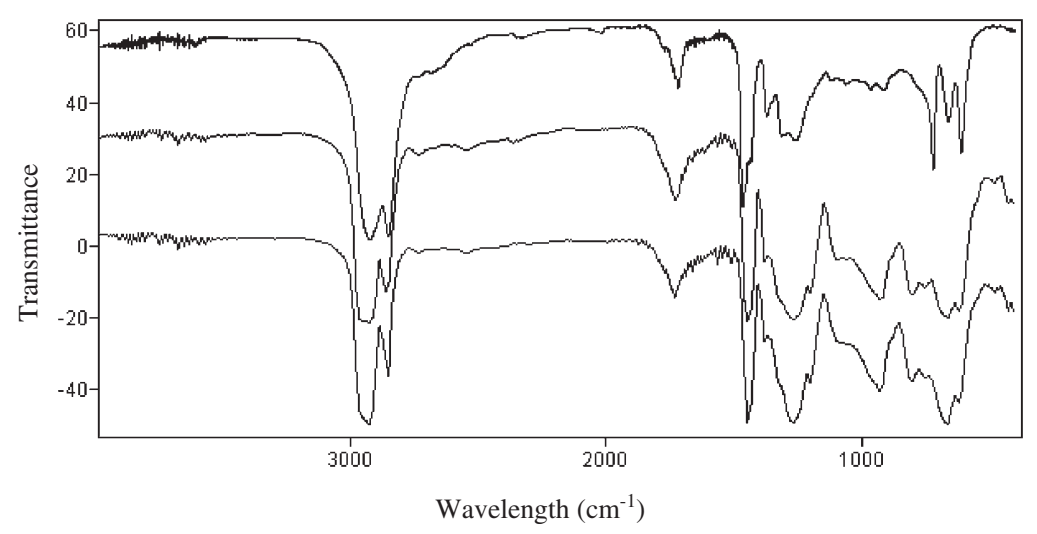

Figure 4. Comparison of FT-IR spectra of samples having above $25 \%$ chlorine.

to the $\mathrm{C}-\mathrm{H}$ stretching mode. ${ }^{16-19}$ Figure 3 illustrates the absorption spectrum of a CPE's sample containing of $13.5 \%$ chlorine. In this spectrum besides of $\mathrm{CH}_{2}$ absorptions peaks, the $\mathrm{C}-\mathrm{Cl}$ stretching and bending modes have been detected by two separated sharp peaks at about 617 and $1267 \mathrm{~cm}^{-1}$ respectively. The absorption vibrations that have been appeared at the region of $800-1100 \mathrm{~cm}^{-1}$ are due to the $\mathrm{C}-\mathrm{C}$ bonds, which resulted from increasing the dipole moments of polymeric chain by formation of $\mathrm{C}-\mathrm{Cl}$ bonds. ${ }^{16-22}$

In Figure 4 the FT-IR spectra of CPE's samples having 25 to $55 \%$ chlorine have been shown. It can be observed that as the reaction proceeds and the number of substituted chlorine atoms along the polymeric back bone increases, the stretching and bending modes of $\mathrm{C}-\mathrm{Cl}$ bonds and the vibrations of $\mathrm{C}-\mathrm{C}$ bonds become stronger. However for quantitative analyzing the H NMR can be helpful.

The variation of molecular structure of $\mathrm{CPE}$ during chlorination reaction can be investigated deeply by the H NMR spectra. Figure 5 shows a CPE's spectrum having $13.5 \%$ chlorine. This Figure shows two significant and separated groups of peaks. The one that has been appeared at the chemical shifts of 1.1-2.4 ppm

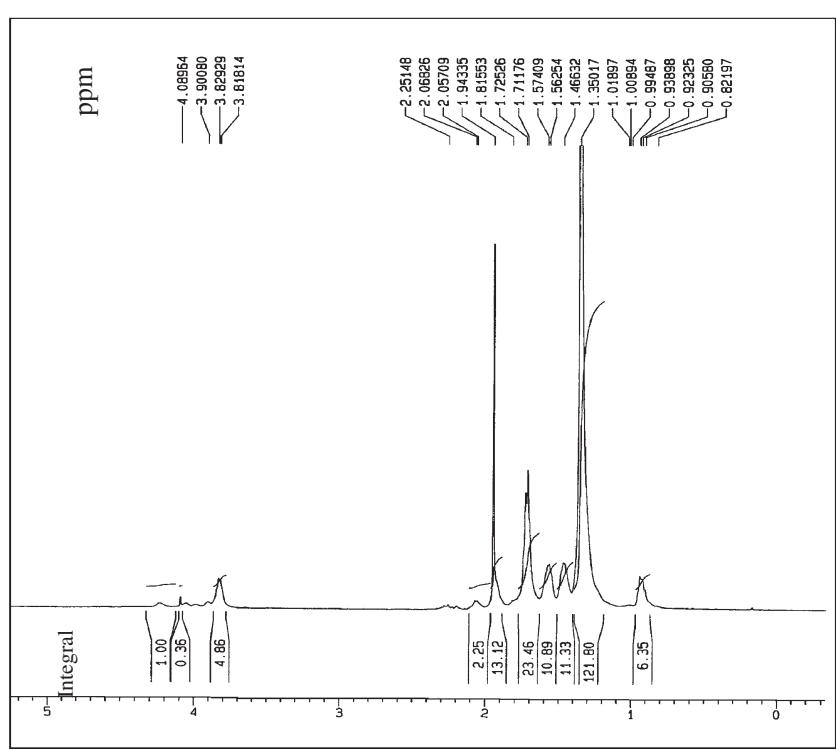

Figure 5. The H NMR spectrum of CPE sample containing $13.5 \%$ chlorine.

corresponds to the methylene $\left(\mathrm{CH}_{2}\right)$ protons and the other which has been appeared at the chemical shifts of $3.7-4.4 \mathrm{ppm}$ is assigned to the chloromethylene 




Figure 6. The H NMR spectrum HDPE powder.

$(\mathrm{CHCl})$ protons. Besides of these two groups of peaks another small group of peaks are also observed at the upper field (chemical shifts lower than $1 \mathrm{ppm}$ ) that could be assigned to the resonance of methyl $\left(\mathrm{CH}_{3}\right)$ protons. As the reaction proceeds the chemical shift of these methyl groups has been shifted towards the methylene groups and eventually they converge. This phenomenon resulted from the decreasing of electronic density around methyl protons due to the induction effect of chlorine atoms that have been substituted at the vicinity of this group of peaks..$^{20,21}$

The Figure 6 illustrates the H NMR spectrum of HDPE powder that has been used in the reaction. In this spectrum the resonance of methylene protons has been appeared at the chemical shift of $1.41 \mathrm{ppm}$ and the resonance of methyl $\left(\mathrm{CH}_{3}\right)$ protons appeared at less than $1 \mathrm{ppm}$. Figure 7 shows the H NMR spectrum of the CPE's sample containing $28 \%$ chlorine. As Figures 5 and 7 shows the first group of peaks (assigned to the methylene protons) comprises a sharp peak at about $1.35 \mathrm{ppm}$ and some other peaks at the chemical shifts higher than this one. As the reaction goes on the integrated value of this sharp peak

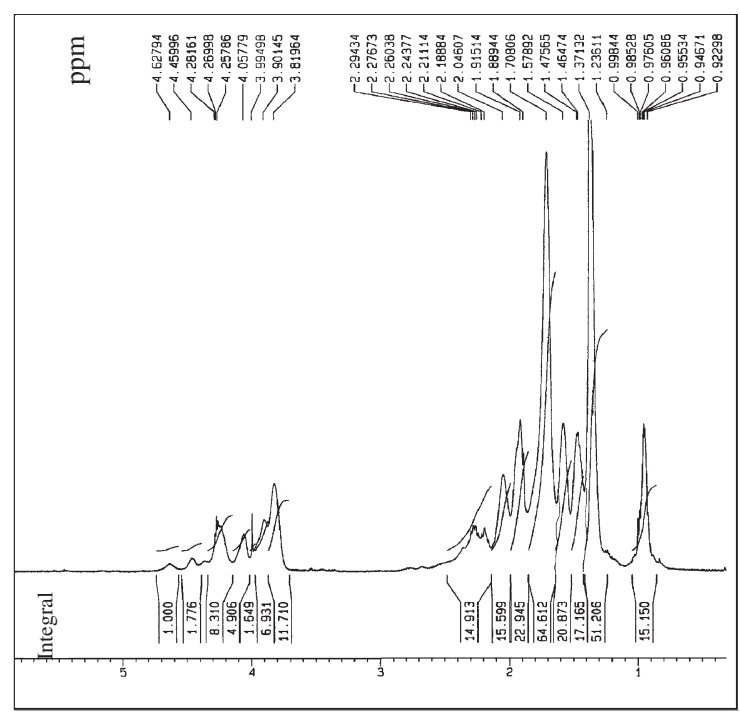

Figure 7. The H NMR spectra of CPE sample containing $28 \%$ chlorine.

decreases and the number of peaks appearing at its vicinity (on left side) increases considerably. The multiplication of the methylene peaks is due to their relative distances from the chloromethylene groups in the polymer chains. To identify the sequences of methylene groups the notation of $\alpha, \beta$ and $\gamma$ have been used to show their distances from $\mathrm{CHCl}$ group (one, two and three or more carbon atoms respectively). Reviewing the chemical shifts of methylene sequences in some model compounds can help us in diagnosing of these sequences. Table I shows some of these model compounds. ${ }^{29,30}$ The H MNR spectrum of $n$-Chloropentane as the first model compound illustrates the sequences of $\alpha, \beta$ and $\gamma$ at the chemical shifts of $1.78,1.44$ and $1.29 \mathrm{ppm}$ respectively. In the H NMR spectrum of 1,12-Dichlorododecane as the second model compound three remarkable peaks are observable at the chemical shifts of $1.79,1.5$, and $1.29 \mathrm{ppm}$. The first chemical shift is assigned to the methylene chemical groups exactly next to the $\mathrm{CHCl}$ groups. The second one corresponds to the methylene group

Table I. Chemical shifts of model compounds sequences

\begin{tabular}{|c|c|c|}
\hline Compounds & $\begin{array}{c}\text { Chemical formula and } \\
\alpha, \beta \text { and } \gamma \text { methylene sequences }\end{array}$ & $\begin{array}{l}\text { Chemical } \\
\text { shifts }\end{array}$ \\
\hline$n$-Chloropentane & $\mathrm{ClCH}_{2}-\underset{\alpha}{\mathrm{CH}_{2}}-\underset{\beta}{\mathrm{CH}_{2}}-\mathrm{CH}_{\gamma}-\mathrm{CH}_{3}$ & $\left\{\begin{array}{l}\alpha=1.8 \\
\beta=1.44 \\
\gamma=1.29\end{array}\right.$ \\
\hline 1,12-Dichlorododecane & $\mathrm{ClCH}_{2}-\underset{\alpha}{\mathrm{CH}_{2}}-\underset{\beta}{\mathrm{CH}_{2}}-\left(\underset{\gamma}{\mathrm{CH}_{2}}\right)_{6}-\underset{\beta}{\mathrm{CH}_{2}}-\mathrm{CH}_{\alpha}-\mathrm{CH}_{2} \mathrm{Cl}$ & $\left\{\begin{array}{l}\alpha=1.79 \\
\beta=1.5 \\
\gamma=1.29\end{array}\right.$ \\
\hline 1,4-Dichlorobutane & $\mathrm{ClCH}_{2}-\mathrm{CH}_{\alpha}-\mathrm{CH}_{\alpha}-\mathrm{CH}_{2} \mathrm{Cl}$ & $\alpha=1.86$ \\
\hline $\mathrm{PVC}$ & $-\mathrm{ClCH}-\mathrm{CH}_{2}-\mathrm{ClCH}-$ & $\alpha=2.19$ \\
\hline
\end{tabular}




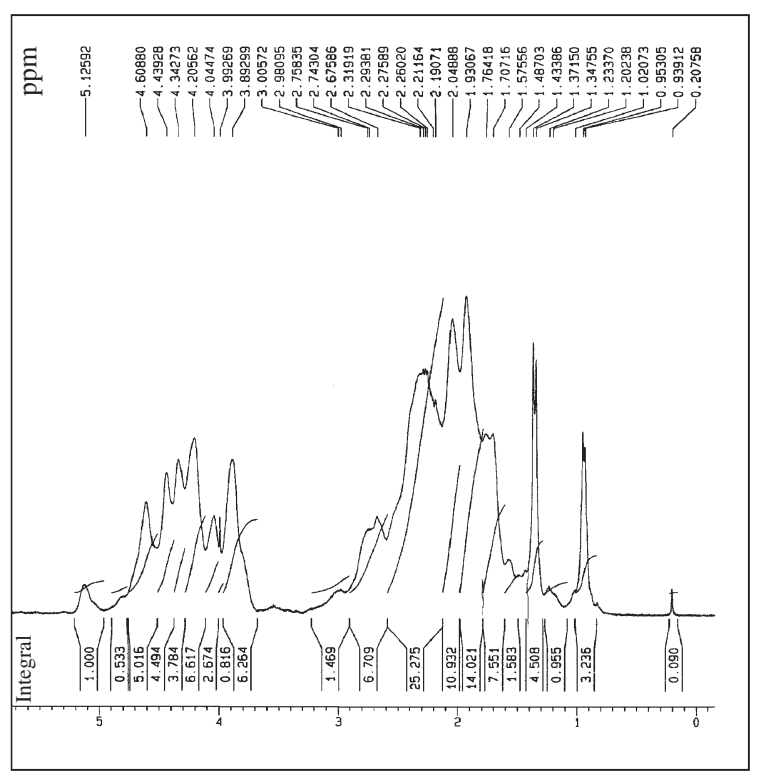

Figure 8. The H NMR spectra of sample containing $54 \%$ chlorine.

that is two carbon atoms far from chloromethylene group. The last chemical shift is assigned to the methylene chemical groups, which are three or more carbon atoms far from the $\mathrm{CHCl}$ groups. Comparing CPE's spectra with the data of model compounds, it can be concluded that the chemical shifts of $1.8 \mathrm{ppm}$ and higher than this are assigned to the $\alpha$ methylene sequences. The chemical shifts of lower than 1.42 $\mathrm{ppm}$ are due to the $\gamma$ methylene sequences and the chemical shifts between these two regions are assigned to the $\beta$ methylene sequences. Figure 8 shows one of samples of CPE spectrum that contains 54\% chlorine. In this spectrum the sequences of methylene and chloromethylene groups can be distinguished.
Comparing Figures 5, 7 and 8 shows that the integration value of $\gamma$ methylene sequences has been decreased while the integration values of $\alpha$ and $\beta$ methylene sequences have been increased. It can be also concluded that as the reaction proceeds the chemical shift of $\alpha$-sequences has been shifted to the higher values, which is consistent with figures of the two model compounds given in Table I (1,4 Dichlorobutane and PVC). The reason of this phenomenon is due to the decreasing of electronic density around the methylene groups resulted from substitution of more chlorine atoms at their vicinity.

The relative fractions $\alpha, \beta$ and $\gamma$ methylene sequences for each spectrum of CPE's samples have been calculated separately and plotted verses chlorine percentage and shown in Figure 9. As one can see from this figure, the percentage of $\alpha$ methylene sequences does not change considerably up to $35 \%$ of chlorination and after that it has been increased exponentially. The percentage of $\beta$ methylene sequences increases moderately to a maximum value around $40 \%$ of chlorination and then decreases with a higher rate. The percentage of $\gamma$ methylene sequences decreases as the chlorination reaction goes on.

Regarding the chloromethylene peaks appeared at the chemical shifts of $3.7-4.5 \mathrm{ppm}$, it can be seen that as reaction proceeds, their number and magnitudes increase. A similar reasoning as above could be also applied to explain this phenomenon.

Another result that can be obtained from H NMR spectra is the degree of chlorination. The chlorine percentage can be computed from integrated value of methylene and chloromethylene groups of peaks in the H NMR spectrum. The calculation procedure is explained below. Let denote the summation of the

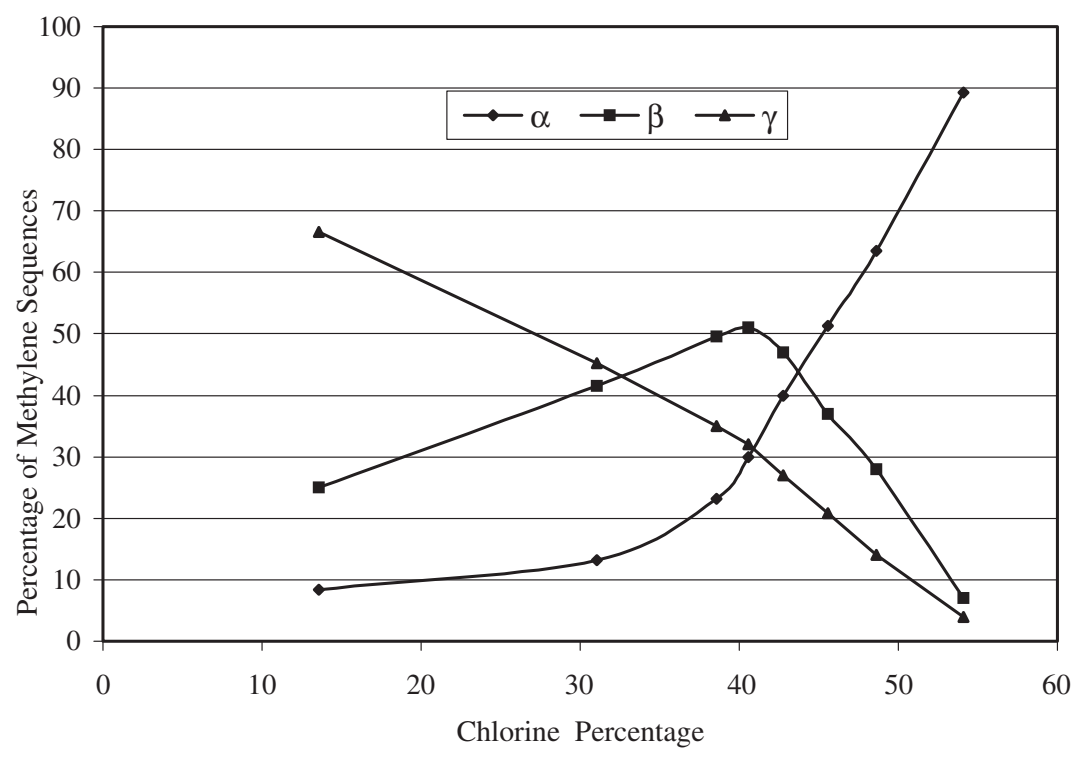

Figure 9. The variations of $\alpha, \beta$ and $\gamma$ methylene sequences $v$ s. chlorine percentage. 


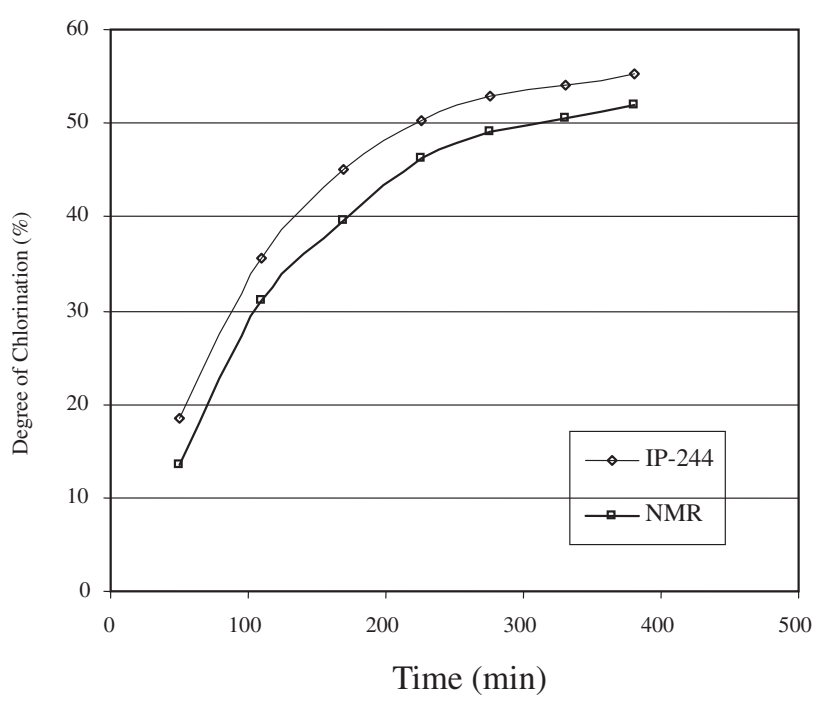

Figure 10. Reaction rate $v s$. time.

integration values of methyl, methylene and chloromethylene protons by $S_{1}, S_{2}$ and $S_{3}$ respectively. Since in the methyl group the number of hydrogen atoms is three times of carbon atoms, in the methylene group it is twice of carbon atoms and in the chloromethylene group the number of chlorine, carbon and hydrogen atoms are equal, the chlorine percentage can be calculated as follows:

$$
\begin{gathered}
\text { Chlorine percentage }=\left(M_{\mathrm{Cl}} \times S_{3}\right) /\left[S_{3} \times M_{\mathrm{CHCl}}\right. \\
\left.+\left(S_{2} / 2\right) \times M_{\mathrm{CH}_{2}}+\left(S_{1} / 3\right) \times M_{\mathrm{CH}_{3}}\right]
\end{gathered}
$$

where $M_{\mathrm{Cl}}, M_{\mathrm{CHCl}}, M_{\mathrm{CH}_{3}}$ and $M_{\mathrm{CH}_{2}}$ indicate the formula weights of $\mathrm{Cl}, \mathrm{CHCl}, \mathrm{CH}_{3}$ and $\mathrm{CH}_{2}$ respectively.

Since the chemical shifts of $\mathrm{CH}_{2} \mathrm{CL}$ and $\mathrm{CHCl}$ are close to each other and their formula weights differ only one unit $\left(M_{\mathrm{CH}_{2} \mathrm{Cl}}=48.5, M_{\mathrm{CHCl}}=47.5\right)$, in the above formula the integration value of $\mathrm{CH}_{2} \mathrm{Cl}$ is included in $\mathrm{CHCl}$ corresponding term.

In this way the chlorine percentage of all samples were calculated and plotted $v$ s. time as shown in the Figure 10. For evaluating the obtained results, these samples have also been analyzed with elemental analyzing flask combustion method (IP-244). The corresponding results are also shown in the Figure 10. This figure shows that both techniques have the same trend but with some differences that could be mostly resulted from the analyzing errors. The reaction rate obtained from flask combustion method is higher than the one obtained from the H NMR calculation. In the flask combustion method, existence of solvent trace in the sample reduces the accuracy of results, where in the H NMR analyzing technique the partially dissolved samples and/or precipitation of CPE's samples can be the most important sources of chlorine miscalculation.

As can be seen from Figure 10 the reaction rate is relatively high up to $50 \%$ chlorination and then it decreases. The decreasing of reaction rate at the final stage can be due to decreasing of intermediate methylene radical formation (caused by chlorine atoms induction effect) and also decreasing the number of $\gamma$ methylene sequences.

\section{CONCLUSIONS}

Radical chlorination of polyethylene in perchloroethylene under atmospheric pressure and different concentrations of polyethylene and chlorine gas at different temperature levels have been carried out and appropriate reaction conditions are determined. The FT-IR spectra of CPE's prepared samples show that as reaction proceeds, the $\mathrm{C}-\mathrm{Cl}$ stretching and bending modes and $\mathrm{C}-\mathrm{C}$ vibrations create a broad peak. Also it is observed that the peak corresponding to $\mathrm{CH}_{2}$ stretching mode become wider due to the induction effect of chlorine atoms added to the polymeric structure. Trough H NMR spectra of samples, $\alpha, \beta$ and $\gamma$ sequences of methylene groups are identified and their quantitative variations respect to degree of chlorination have been determined. Using the integration values of methylene and chloromethylene group of peaks, the degree of chlorination is estimated in each sample and the results are compared with those obtained from flask combustion method. It has been observed that there are some discrepancies between results obtained from these two methods, while regarding the degree of chlorination they show the same trends. The differences can be mostly due to the technical problem such as CPE precipitation during $\mathrm{H} \mathrm{NMR}$ test or solvent residual remained in the chlorinated polymer. As reaction proceeds, the reaction rate decreases which can be due to decreasing of intermediate methylene radical formation and also because of decreasing the number of $\gamma$ methylene sequences.

\section{REFERENCES}

1. J. Kroschwite, H. F. March, and N. M. Gaylord, "Encyclopedia of Polymer Science and Technology. Polyethylene Compounds," John Wiley and Son's, New York, N.Y., 1985, p 495.

2. W. Nishimoto and K. B. Sinclair, "Chlorinated Polyethylene,” SRI International No. 83, Stanford Research Institute, Menlo Park, CA, 1984.

3. J. C. Salamone, "Polymeric Material Encyclopedia," CRC Press, Boca Raton FL, 1996, p 1235.

4. N. Ito, K. Okayama, T. Karasuda, and Y. Migagawa, "Process for the Preparation of Chlorinated Polyolefins and Chlorosulfonated Polyolefin," US. Patent 5378766, 1995.

5. T. Nakagawa, M. Narui, and Y. Sakanaka, "Method of Making Chlorosulfonated Polyethylene," US. Patent 4871815, 1989. 
6. M. Narui, "Method of Chlorination or Chlorination and Chlorosulfonation,” JP. Patent 63172702, 1988.

7. Y. Ishida and K. Okayama, "Process for Producing Chlorinated Polyolefin," US. Patent 5290879, 1994.

8. D. J. Ryan, "Chlorination and Chlorosulfonation of Polyethylene in Mixed Solvent," US. Patent 4145491, 1979.

9. E. G. Brugel, "Process for Chlorination and Chlorosulfonation of Olefins Polymers in Suspensions of Perflorinated Liquids," US. Patent 5242987, 1993.

10. C. Bish, E. G. Brugle, and R. F. Eniss, "Process for Preparation and Chlorosulfonation of Olefin Polymer Having Low Level of Residual Monoflorobenzene Reaction Solvent and Its Chlorinated Byproducts,” US. Patent H1, 582, 1996.

11. Y. Ishida and K. Okayama, "Process for Producing Chlorinated Polyethylene in Presences of Olefin," US. Patent 5212254, 1993.

12. R. R. Blanchard, "Chlorosulfonation of Chlorinated Polyethylene," US. Patent 4584351, 1986.

13. R. Zhao, S. Cheng, Y. Shun, and Y. Huang, J. Appl. Poly. Sci., 81, 3582 (2001).

14. M. C. Elisa and T. J. McCarthy, Macromolecules, 25, 2603 (1992).

15. V. Tricoli and N. Cerretta, Electrochem. Commun., 4, 272 (2002).

16. A. J. Varma, P. Kondapalli, S. V. Deshpande, and S. P. Kokane, Polym. Degrad. Stab., 63, 5 (1999).

17. K. Nambu, J. Appl. Polym. Sci., 4, 69 (1960).

18. B. Bikson, J. G. Joseph, and D. Vosfi, Polymer, 22, 641 (1981).

19. M. A. Smook, E. T. Pieski, and C. F. Hammer, Ind. Eng. Chem., 45, 2731 (1953).
20. R. M. Silvershtin, G. C. Bassler, and T. S. Morile, "Spectrometric Identification of Organic Compounds," John Wiley and Sons Inc, New York, N.Y., 1991.

21. D. L. Pavia, G. M. Lapman, and G. S. Kriz, "Introduction to Spectroscopy Analyzing,” W. B. Saunders Company, Philadelphia, PA, 1987.

22. B. Magloire, B. Philippe, and V. Georges, Polym. J., 7, 287 (1975).

23. C. Zhikuan and S. Lianghe, Polymer, 25, 369 (1984).

24. B. H. Chang, R. Zeigler, and A. Hiltner, Polym. Eng. Sci., 28, 1167 (1988).

25. B. H. Chang, J. W. Dal, A. Siegmann, and A. Hiltner, Polym. Eng. Sci., 28, 1173 (1988).

26. A. Moradi, A. Ramazani Saadatabadi, and M. Shahrokhi, "Radical Chlorination of HDPE/LDPE Under Atmospheric Pressure," The 6th Iranian Seminar on Polymer Science and Technology, Tehran, Iran, 2003.

27. A. Moradi, A. Ramazani Saadatabadi, and M. Shahrokhi, "Photochlorination of Polyethylene in Atmospheric Pressure," The 10th APCChE Congress, Kitakyushu, Japan, 2004.

28. Standard Method for Analysis and Testing of Petroleum and Related Products. IP-244, Institute of Petroleum London, London, U.K., 1998.

29. S. Philip, "Sadtler, N.M.R Standard Spectra," Sadtler Research Laboratories, Subsidiary of Block Engineering, Philadelphia, PA, 1976, 21.

30. S. Philip, "Sadtler, Standard N.M.R. Spectra," Sadtler Research Laboratories Subsidiary of Block Engineering, Philadelphia, PA, 1976, 26. 